\title{
Resistance to Phytophthora nicotianae in Tobacco Breeding Lines Derived from Variety Beinhart 1000
}

Kestrel McCorkle, Department of Plant Pathology, Ramsey Lewis, Department of Crop Science, and David Shew, Department of Plant Pathology, North Carolina State University, Raleigh

\begin{abstract}
McCorkle, K., Lewis, R., and Shew, D. 2013. Resistance to Phytophthora nicotianae in tobacco breeding lines derived from variety Beinhart 1000. Plant Dis. 97:252-258.

Black shank, caused by Phytophthora nicotianae, is managed primarily by host resistance. The rapid emergence of race 1 eliminated the usefulness of available complete resistance, leading breeders to search for new sources of resistance. Cigar tobacco 'Beinhart 1000' $(\mathrm{BH})$ is highly resistant to all races of $P$. nicotianae. Doubled-haploid (DH) lines from a cross of BH and the susceptible 'Hicks' were evaluated for black shank resistance, and quantitative trait loci (QTL) on linkage groups (LGs) 4 and 8 accounted for $>43 \%$ of the phenotypic variation

genotypes with one or both QTL from BH on LGs 4 and 8 had increased incubation periods and decreased root rot but higher final inoculum levels than genotypes with neither QTL. A low level of stem resistance was observed in $\mathrm{BH}$ and $\mathrm{DH}$ lines with the QTL from $\mathrm{BH}$ on LG 4 but not LG 8. Low levels of leaf resistance were seen for Hicks, $\mathrm{BH}$, and DH lines with both QTL from BH on LG 4 and 8. The partial resistance from $\mathrm{BH}$ has not been used commercially and may provide an increase in level of partial resistance in future tobacco varieties.
\end{abstract} in resistance. Forty-three DH lines and parents were evaluated, and
Black shank, caused by the oomycete Phytophthora nicotianae, was first reported in Java in 1896 by Van Breda de Haan (4), and now is present in many tobacco-growing regions worldwide $(24,32)$. In the United States, the disease was reported in Georgia in 1915, in North Carolina in 1931, and soon afterward in other tobacco-growing regions in the country (24). Black shank can be very damaging to tobacco, with losses in North Carolina averaging about $3.4 \%$ of the crop in the last 3 years, with a mean loss of over $\$ 20$ million dollars per year (27).

Management of black shank requires an integrated approach, but the most important management strategy is the incorporation of complete or partial resistance into commercial varieties of tobacco. Complete resistance to race 0 , the wild-type race of the pathogen, is conferred by the $P h p$ and $P h l$ genes introgressed into Nicotiana tabacum L. from N. plumbaginifolia Viv. and N. longiflora Cav., respectively $(7,18,38)$. The $P h p$ gene is currently incorporated into many flue-cured and burley tobacco varieties (27). Once the Php gene was incorporated into widely accepted flue-cured varieties, rapid shifts in pathogen populations from race 0 to race 1 were observed $(3,9,35)$. The $P h l$ gene has been used sparingly, and only in a few burley tobacco varieties such as 'KY14xL8', but also resulted in shifts in the pathogen population to race 1 (27). Typically, races are identified by inoculating the roots of a set of host differentials and recording symptom expression over time.

Planting of varieties with either the $P h p$ or $P h l$ gene can result in race shifts from race 0 to race 1 in as little as one growing season but the frequency of occurrence increases with continuous planting $(1-3,23,24,33,35)$. Additional races of $P$. nicotianae include races 2 and 3. However, race 2 has only been reported in South Africa and is not a concern for North Carolina growers $(2,3,14,26,39)$. Race 3 is virulent on varieties with the $P h l$ gene but not varieties with the

Corresponding author: K. McCorkle, E-mail: krlannon@ncsu.edu

* The $\boldsymbol{e}$-Xtra logo stands for "electronic extra" and indicates that two supplementary tables are included in the online edition.

Accepted for publication 29 August 2012.

http://dx.doi.org/10.1094/PDIS-05-12-0480-RE

(C) 2013 The American Phytopathological Society
$P h p$ gene $(14,26)$ and, because the $P h l$ gene is not used widely, this race is of little consequence to tobacco growers.

In addition to complete resistance, partial resistance has been incorporated into most commercial tobacco varieties. The primary source of this quantitative resistance is from the cigar tobacco 'Florida 301' (37). Florida 301 exhibits partial resistance to all races but resistance is expressed only in host roots. Continuous planting of varieties with high levels of partial resistance usually results in an increased level of pathogen aggressiveness $(12,35)$. Although many varieties possess resistance derived from Florida 301, extensive losses can occur in plants with this source of resistance. These losses have led breeders to look for additional sources of high levels of partial resistance $(6,38,43)$.

The cigar tobacco 'Beinhart 1000' $(\mathrm{BH})$ was derived from a selection of tobacco 'Quin Diaz' and expresses a high level of partial resistance to both race 0 and race 1 of $P$. nicotianae. Unlike Florida 301, however, several studies have reported the presence of varying levels of resistance to $P$. nicotianae in aboveground tissues of $\mathrm{BH}(8,16,28,36,44)$. In a prior investigation of genomic regions associated with $\mathrm{BH}$ resistance, $\mathrm{BH}$ was crossed with the highly susceptible flue-cured 'Hicks' $(40,42)$. A doubled-haploid (DH) population of 118 lines was subsequently produced from this cross, and a genetic linkage map consisting of 24 linkage groups (LGs) was generated using microsatellite markers and quantitative trait loci (QTL) analysis $(5,22,42)$. Six QTL on LGs $2,4,8,9,11$, and 14 were identified as being associated with black shank resistance, with QTL on LGs 4 and 8 explaining approximately $43 \%$ of phenotypic variation in plant survival $(40,42)$. Several genes involved in the accumulation of certain leaf surface exudates (cisabienol and sucrose esters) are closely linked to the QTL associated with black shank resistance on LG 4 . The genetic variability present on LGs 4 and 8 may be of value for increasing the level of partial resistance to black shank in tobacco. However, little is known about the mechanisms of resistance underlying these QTL.

The main objective of this study was to quantify components of resistance in roots of $\mathrm{DH}$ lines derived from resistant parent $\mathrm{BH}$ (42). Experiments also were conducted to determine whether resistance, conferred by QTL on LGs 4 and 8, is expressed in stem and leaf tissues. The DH lines containing different combinations of resistant $\mathrm{BH}$ alleles on LGs 4 and 8 were used for this investigation. 


\section{Materials and Methods}

Forty-three DH lines derived from a cross between resistant $\mathrm{BH}$ and susceptible Hicks were tested for root, stem, and leaf resistance to P. nicotianae. Lines were selected based on the presence or absence of the Hicks and $\mathrm{BH}$ genomic regions (based on microsatellite marker genotyping) corresponding to QTL on LGs 4 and 8 (42). An attempt was made to select lines so that segregation at other marker loci did not differ significantly from a 1:1 ratio within each group. Special attention was paid to genomic regions previously identified to be associated with resistance (42). This resulted in four groups plus the parents for use in experiments. The four groups consisted of group 4B8B (11 lines carrying BH genomic regions corresponding to QTL on LGs 4 and 8 ), group 4B8H (11 lines carrying the favorable $\mathrm{BH}$ genomic region on $\mathrm{LG} 4$ and the Hicks genomic region corresponding to the identified QTL on LG 8), group 4H8B (12 lines carrying the Hicks genomic region on LG 4 and the $\mathrm{BH}$ genomic region corresponding to the QTL on LG 8), and group 4H8H (9 lines carrying the Hicks genomic regions corresponding to QTL on LGs 4 and 8).

Seed of each line were sown onto potting mix (Fafard 2 Mix; Conrad Fafard, Inc.) in plastic pots in a greenhouse and 3-week-old seedlings were transplanted into 10 -cm clay pots filled with a 1:1:1 ( $\mathrm{vol} / \mathrm{vol} / \mathrm{vol})$ mixture of steam-pasteurized $\left(80^{\circ} \mathrm{C}\right.$ for $\left.30 \mathrm{~min}\right)$ sandy-loam soil, coarse builder's sand, and potting medium (Fafard 4P Mix; Conrad Fafard, Inc.). Plants were watered daily and fertilized once a week with 20-20-20 Miracle-Gro (The Scotts MiracleGro Company). Plants were fertilized full-strength ( $\mathrm{N}$ at $200 \mathrm{ppm}$ ) 1 week after planting and half-strength $(\mathrm{N}$ at $100 \mathrm{ppm})$ the remaining weeks of all experiments. The greenhouse was maintained at 35 and $25^{\circ} \mathrm{C}$ day and night temperatures, respectively, with supplemental lighting for $12 \mathrm{~h}$ per day starting at 8:00 a.m.

Pathogen maintenance. The race 0 isolate, F06 4-24.7, used in greenhouse studies was obtained from a research plot at the Central Crops Research Station in Clayton, NC. The plot was planted with tobacco 'K326', and the isolate was obtained from the root zone of a symptomatic plant using a semi-selective agar medium as described by Sullivan et al. (34).

The semi-selective medium PARPH was prepared by autoclaving $18 \mathrm{~g}$ of Bacto Agar (Difco Laboratories) in $200 \mathrm{ml}$ of clarified V8 juice and $800 \mathrm{ml}$ of deionized (DI) water for $30 \mathrm{~min}$ at $121^{\circ} \mathrm{C}$. Medium was cooled to $55^{\circ} \mathrm{C}$ and the following chemicals were suspended in $25 \mathrm{ml}$ of DI water before addition: $125 \mathrm{mg}$ of pentachloronitrobenzene, $50 \mathrm{mg}$ of hymexazol, and $250 \mathrm{mg}$ of ampicillin (21). Additional antibiotic suspensions were also added: $2 \mathrm{ml}$ of rifamycin stock $(500 \mathrm{mg}$ of rifamycin SV sodium salt in $100 \mathrm{ml}$ of $95 \% \mathrm{EtOH}$ ) and $2 \mathrm{ml}$ of pimaricin stock (500 $\mathrm{mg}$ of natamycin in $100 \mathrm{ml}$ of sterile DI water) were stirred into the medium. After amendments, $18 \mathrm{ml}$ of PARPH was poured into each 9-cm Petri dish. Stock cultures of the pathogen were maintained on $5 \%$ clarified $\mathrm{V} 8$ medium at $28^{\circ} \mathrm{C}$ in the dark.

Evaluation of root resistance. This experiment was arranged in a randomized complete block design with 10 replications (plant $=$ experimental unit) per treatment, and the experiment was conducted three times. The 5-week-old seedlings ( 2 weeks after transplanting to the soil medium) were inoculated with oat grains that were colonized by $P$. nicotianae. Oat grains were prepared by autoclaving $500 \mathrm{ml}$ of oat and $300 \mathrm{ml}$ of DI water at $121^{\circ} \mathrm{C}$ for $1 \mathrm{~h}$ once a day for three consecutive days. Sterilized oat grains were added to pathogen-colonized 5\% V8 cultures, sealed with Parafilm, and incubated at 22 to $26^{\circ} \mathrm{C}$ in light for 7 to 12 days. A single oat grain was placed into each of four separate 5-cm-deep holes made $4 \mathrm{~cm}$ from the stem of each plant with a $1 \mathrm{~cm}$-diameter bamboo plant stake. Plants were watered after inoculation to seal the holes. Control plants received no inoculum in the four holes around the plant.

Incubation period was determined as the number of days required for first aboveground symptoms to occur. Plants were watered $1 \mathrm{~h}$ prior to rating each morning to eliminate possible rating of transient wilting for disease. First symptoms included signifi- cant wilting or presence of a stem lesion. Plants were rated for 21 days, at which time roots of control plants had filled their pots. Final disease incidence was determined as the percentage of plants with symptoms on day 21 . Because not all plants developed symptoms during the 21-day rating period, a previously described severity index of 0 to 10 was used to compare lines for incubation period (34). Severity values of 0 to 10 were based on when symptoms first appeared and included 2 to 5 days $=10,6$ to 9 days $=8,10$ to 13 days $=6,14$ to 17 days $=4,18$ to 21 days $=2$, and no symptoms at day $21=0$. On day 21 , roots of each plant were washed free of soil and the remaining root system rated for percent root rot.

Prior to watering on day 21, two soil cores were taken from each pot in three randomly selected replications of the experiment. The two soil cores from each pot were combined and three subsamples were assayed for pathogen populations by suspending $0.3 \mathrm{~g}$ of soil in $20 \mathrm{ml}$ of DI water and pouring the suspension over five $10-\mathrm{cm}$ Petri dishes containing PARPH. Dishes were incubated for 2 days in light at $25^{\circ} \mathrm{C}$ before washing soil from the medium. Colonies of $P$. nicotianae for each subsample were counted and converted to propagules per gram of dry soil.

Analysis of variance and multiple comparisons were made using PROC GLM of SAS (version 9.2; SAS Institute) for severity index and secondary inoculum production, and PROC MIXED for percent root rot. Single degree of freedom contrast statements were used to compare between different groups of lines for measured characteristics.

Evaluation of stem resistance. This experiment was arranged in a randomized complete block design with five replications (plant $=$ experimental unit) in run 1 and six replications in run 2 . The 43 DH lines, $\mathrm{BH}$, and Hicks were used in the stem inoculation testing. Plants were maintained under the same conditions previously mentioned, with seedlings transplanted at 3 weeks of age and inoculated at 8 to 9 weeks of age.

Multiple inoculation methods have been used to quantify levels of disease resistance in above-ground tissues $(14,17,25,29,31,39)$. For our tests, plants were inoculated with pathogen-infested toothpicks 5 to 6 weeks after transplanting, when plants were a minimum of $30 \mathrm{~cm}$ in height. Infested toothpicks were prepared by cutting rounded wooden toothpicks, 65 by $2 \mathrm{~mm}$ (HOME 360, distributed by DZA Brands, LLC), in half and then autoclaving them in $5 \% \mathrm{~V} 8$ broth for $30 \mathrm{~min}$ at $121^{\circ} \mathrm{C}$ once a day for three consecutive days. Sterilized toothpicks were placed on the surface of 5\% V8 agar cultures of the pathogen. Dishes were sealed with Parafilm and stored under light at room temperature for 7 days. After 7 days, colonized toothpicks were removed from the agar and used within several hours to inoculate plant stems (11). Toothpicks were inserted into stems between the fourth and fifth nodes. Noninfested toothpicks were used to stab control plants.

Plants were rated at the same time each day for five consecutive days and lesion lengths were measured using a digital caliper. Analysis of variance and multiple comparisons among treatments were conducted using PROC GLM of SAS (version 9.2; SAS Institute).

Evaluation of leaf resistance. The $43 \mathrm{DH}$ lines and parents were evaluated for leaf resistance to $P$. nicotianae by inoculating leaves grown under greenhouse conditions. Leaf resistance has been determined by inoculating whole leaves or strips of leaves with infested agar plugs or a zoospore suspension $(29,36)$. For our experiments, we collected leaves from greenhouse plants 5 to 6 weeks after transplanting (8- to 9-week-old-plants) and inoculated the detached leaves with zoospore suspensions as described below. Plants were grown in the greenhouse as described above.

Multiple isolates of $P$. nicotianae were screened for consistent and abundant production of zoospores under lab conditions. A race 0 isolate, VA 408, that was obtained from a soil assay of infested soil collected in a field with black shank in Halifax County, VA in 2007 was selected for all leaf inoculations. This isolate consistently produced high numbers of zoospores and readily infected leaf tissues of susceptible plants in preliminary experiments. 
The isolate was grown on oatmeal agar (Difco Laboratories) in the dark at $28^{\circ} \mathrm{C}$ to obtain hyphal mats. After 2 weeks, hyphal mats were peeled from the agar surface, cut in half, placed in $20 \mathrm{ml}$ of sterile 5\% soil extract, and sealed with Parafilm. Soil extract was prepared by suspending $50 \mathrm{~g}$ of soil from the root zone of tobacco plants in 1 liter of DI water for 2 days. The suspension was filtered through filter paper (Fisherbrand qualitative P8 course porosity, catalog number $09-795 \mathrm{~F}$ ) to remove soil particles, then autoclaved for 30 min at $121^{\circ} \mathrm{C}$. Hyphal mats were placed in Petri dishes with soil extract, incubated in the dark for 3 days at $28^{\circ} \mathrm{C}$, then washed three times with DI water. After hyphal mats were washed, $20 \mathrm{ml}$ of fresh soil extract was added to each dish. To induce zoospore release, hyphal mats were refrigerated for $30 \mathrm{~min}$ and then brought to room temperature. Zoospore concentration was determined by counting the number of zoospores in five $0.25-\mu l$ drops under a compound microscope just prior to use.

Six plants of each of the 45 plant genotypes were grown to provide leaves for each of the two runs of the experiment. Two leaves of approximately the same size were collected from the third and fourth node of each plant and placed into a large plastic moist chamber ( 22.5 by 32.5 by $5 \mathrm{~cm}$ ) with a water reservoir in the bottom of the container. Leaves were suspended over the water on a wire mesh (hardware cloth). Moist chambers were arranged in a randomized complete block design. In run 1 of the experiment, each leaf was inoculated at two locations with a 40- $\mu$ aliquot of zoospore suspension containing 100 zoospores/ $\mu$ l. Leaves in run 2 of the experiment were inoculated at four locations. For both runs, inoculation sites were $25 \mathrm{~mm}$ from the midvein on either side of the leaf. Leaves were incubated between 28 and $30^{\circ} \mathrm{C}$ for 4 days in light. Infection efficiency was recorded daily, with final infection efficiency taken on day 4. Leaves were rated at the same time daily for three consecutive days, with the first symptoms observed $24 \mathrm{~h}$ after inoculation. Infection efficiency was calculated by dividing the number of lesions by the total number of inoculation sites. Analysis of variance and multiple comparisons were made among genotype groups using PROC MIXED of SAS (version 9.2; SAS Institute).

\section{Results}

Root resistance. Moderate to high levels of disease developed in all DH groups and parental lines in all three runs of the experi-

Table 1. Disease incidence in tobacco breeding lines sorted into doubledhaploid (DH) groups and parental lines when inoculated with Phytophthora nicotianae in a greenhouse ${ }^{\mathrm{a}}$

\begin{tabular}{|c|c|c|c|}
\hline Run & $\begin{array}{l}\text { DH group } \\
\text { or parent }\end{array}$ & $\begin{array}{c}\text { Number } \\
\text { of plants }\end{array}$ & $\begin{array}{c}\text { Incidence (\%) } \\
\pm \mathrm{SE}^{\mathrm{d}}\end{array}$ \\
\hline 1 & $4 \mathrm{H} 8 \mathrm{H}$ & 90 & $100 \pm 0$ \\
\hline 1 & $4 \mathrm{~B} 8 \mathrm{H}$ & 109 & $92 \pm 7$ \\
\hline 1 & $4 \mathrm{H} 8 \mathrm{~B}$ & 119 & $96 \pm 4$ \\
\hline 1 & 4B8B & 109 & $79 \pm 8$ \\
\hline 1 & BH & 10 & 70 \\
\hline 1 & Hicks & 10 & 100 \\
\hline 2 & $4 \mathrm{H} 8 \mathrm{H}$ & 90 & $100 \pm 0$ \\
\hline 2 & $4 \mathrm{~B} 8 \mathrm{H}$ & 110 & $86 \pm 5$ \\
\hline 2 & $4 \mathrm{H} 8 \mathrm{~B}$ & 120 & $82 \pm 7$ \\
\hline 2 & $4 \mathrm{~B} 8 \mathrm{~B}$ & 110 & $56 \pm 8$ \\
\hline 2 & BH & 10 & 50 \\
\hline 2 & Hicks & 10 & 100 \\
\hline 3 & $4 \mathrm{H} 8 \mathrm{H}$ & 90 & $100 \pm 0$ \\
\hline 3 & $4 \mathrm{~B} 8 \mathrm{H}$ & 110 & $84 \pm 8$ \\
\hline 3 & $4 \mathrm{H} 8 \mathrm{~B}$ & 120 & $82 \pm 7$ \\
\hline 3 & $4 \mathrm{~B} 8 \mathrm{~B}$ & 110 & $66 \pm 6$ \\
\hline 3 & BH & 10 & 0 \\
\hline 3 & Hicks & 10 & 100 \\
\hline
\end{tabular}

a Disease incidence was calculated for 5 week-old tobacco seedlings that were inoculated with infested oat grains.

' Groups based on presence or absence of 'Beinhart 1000' (BH) black shank resistance quantitative trait loci on linkage group 4 and 8 .

${ }^{c}$ Number of plants observed for symptom development.

${ }^{\mathrm{d}}$ Mean disease incidence for each group of lines 21 days after inoculation with $P$. nicotianae. ment under the highly favorable conditions in the greenhouse. There was a significant run and genotype-run interaction for all variables $(P<0.005)$, indicating that individual lines responded differently across runs. Therefore, data from each run were analyzed separately for disease severity, percent root rot, and secondary inoculum production.

Disease incidence reached $100 \%$ in all three runs of the experiment for plants of the susceptible parent Hicks and the susceptible $\mathrm{DH}$ group $4 \mathrm{H} 8 \mathrm{H}$. The lowest disease incidence was observed for $\mathrm{BH}$, where 0 to $70 \%$ of the plants became symptomatic within 21 days of inoculation across runs. Mean disease incidence in plants in $\mathrm{DH}$ groups $4 \mathrm{H} 8 \mathrm{~B}$ and $4 \mathrm{~B} 8 \mathrm{H}$ was 82 to $96 \%$ across runs, while mean incidence for plants in group 4B8B was between 56 and $79 \%$ across runs (Table 1).

Because not all plants exhibited aboveground symptoms over the 21-day period, a severity index was used to compare groups of plants for level of resistance to the pathogen. Ranking of groups was similar across all runs, with $\mathrm{BH}$ having the lowest severity index and Hicks and group $4 \mathrm{H} 8 \mathrm{H}$ the highest (Table 2). For example, in run 1, disease severity ranged from 1.4 in $\mathrm{BH}$ to 8.2 in Hicks and 8.3 in group $4 \mathrm{H} 8 \mathrm{H}$ (Table 2). Disease severity was similar in groups $4 \mathrm{~B} 8 \mathrm{H}$ and $4 \mathrm{H} 8 \mathrm{~B}$ but was higher in each of those groups than in 4B8B (Table 3). Single-degree-of-freedom contrasts between DH groups and parents indicated significant differences in all comparisons, except with Hicks versus $4 \mathrm{H} 8 \mathrm{H}$ and $4 \mathrm{~B} 8 \mathrm{H}$ versus 4H8B (Table 3).

Variation in disease severity within $\mathrm{DH}$ groups was greatest in groups carrying the BH QTL on LG 4 or LG 8. For example, in group $4 \mathrm{H} 8 \mathrm{H}$, which had a mean severity of 8.3 , severity values were 4 to 10 . In contrast, groups $4 \mathrm{~B} 8 \mathrm{H}$, mean severity of 6.3 ; $4 \mathrm{H} 8 \mathrm{~B}$, mean severity of 6.6 ; and $4 \mathrm{~B} 8 \mathrm{~B}$, mean severity of 4.0 all had entries with severity values of 0 to 10 .

All inoculated plants developed root rot during the 21-day experiment but none of the controls developed disease or root discoloration. In general, root rot was very high. There was a significant run $(P<0.05)$ and genotype-run interaction for root rot; therefore, data from runs of the experiment were analyzed separately.

For all runs, the greatest level of root necrosis was observed for Hicks and group 4H8H (99 to 100\%). The lowest level of root rot was observed on $\mathrm{BH}$ (17 to $29 \%$ ) across all runs (Table 2). Groups containing BH QTL on either LG 4 or LG 8 had only slightly decreased levels of root rot compared with the susceptible groups, from 90 to $96 \%$ across runs, and average levels of root rot in group 4B8B were 69 to $81 \%$ across runs (Table 2). In run 1, no significant difference in percent root rot was observed between the groups $4 \mathrm{~B} 8 \mathrm{H}$ and $4 \mathrm{H} 8 \mathrm{~B}$ but both of these groups exhibited less root rot than the susceptible parent group (Table 4). Effects of BH QTL on LGs 4 and 8 were more than an additive in reducing root rot. Single-degreeof-freedom contrasts between DH groups and parents were significant (Table 4). The only comparisons that were statistically nonsignificant were Hicks versus $4 \mathrm{H} 8 \mathrm{H}, 4 \mathrm{H} 8 \mathrm{H}$ versus $4 \mathrm{H} 8 \mathrm{~B}$, and $4 \mathrm{~B} 8 \mathrm{H}$ versus $4 \mathrm{H} 8 \mathrm{~B}$. Individual lines within each group showed varying levels of root resistance, with some plants exhibiting $100 \%$ root necrosis in every group, except for the resistant parent $\mathrm{BH}$. Percent root rot within $\mathrm{DH}$ groups $4 \mathrm{H} 8 \mathrm{~B}$ and $4 \mathrm{~B} 8 \mathrm{H}$ had a larger within-group variance than lines in $4 \mathrm{H} 8 \mathrm{H}$ (data not presented).

High numbers of propagules were recovered in all groups and parental lines. There was a significant run and genotype-run interaction $(P<0.05)$, indicating differences in the levels of disease in individual line responses across runs. Therefore, runs were analyzed separately.

Variability within all groups was high and group ranking varied among runs. For example, BH had inoculum levels between 132 and 325 propagules/g across runs, with the highest inoculum density of any treatment at the end of the experiment in two of three runs. Hicks exhibited levels of secondary inoculum similar to that for $4 \mathrm{~B} 8 \mathrm{H}$ and $4 \mathrm{H} 8 \mathrm{~B}$. Group $4 \mathrm{H} 8 \mathrm{H}$ had significantly fewer propagules per gram than group 4B8B in two of three runs (Table 2). Single-degree-of-freedom contrasts between $\mathrm{DH}$ groups $4 \mathrm{~B} 8 \mathrm{H}$, 
4H8B, and 4B8B were not significant. However, the contrast between group 4H8H and 4B8B was significant (Table 5).

Stem resistance. All genotypes developed stem lesions, which were first observed 2 days after inoculation. Results were similar across runs $(P<0.05)$; therefore, data were combined across runs for analysis. Hicks had the largest average lesion size at $110 \mathrm{~mm}$ and $\mathrm{BH}$ had the smallest at $92 \mathrm{~mm}$. Average lesion length for groups of DH lines fell between the parents. Lines in group 4B8B were similar to $\mathrm{BH}$, with a mean lesion length of $93 \mathrm{~mm}$. Groups 4B8H and 4H8B had an average lesion length of 95 and $102 \mathrm{~mm}$, respectively. Groups 4H8B and 4B8B also were different, but no other single-degree-of-freedom comparisons among DH groups were significant (Supplementary Table S1).

Leaf resistance. Leaf lesions developed in all DH groups and parental lines in both runs of the experiment. Results in inoculum efficiency were similar across runs $(P<0.05)$; therefore, data from both runs were combined for analysis.

The average infection efficiency for Hicks was 0.57 (57\% of inoculation sites developed lesions) and was similar to the infec- tion efficiency for BH, 0.50. Both parental lines fell between infection efficiencies of the four DH groups. Group 4B8B had the lowest average infection efficiency, 0.42 , and was not significantly different from $\mathrm{BH}$. The remaining $\mathrm{DH}$ groups $4 \mathrm{~B} 8 \mathrm{H}, 4 \mathrm{H} 8 \mathrm{~B}$, and $4 \mathrm{H} 8 \mathrm{H}$ had similar infection efficiencies, ranging from 0.64 to 0.71 (Supplementary Table S2).

\section{Discussion}

Partial resistance has been the primary type of host resistance used to manage the black shank disease of tobacco since the 1930s (37). A majority of genes controlling this partial resistance were transferred from the cigar tobacco Florida 301. Varying levels of partial resistance are present in most commercial flue-cured and burley tobacco cultivars worldwide $(24,27,31,41,43)$, and likely are the result of incorporation of varying numbers of QTL originating from Florida 301. BH is also a cigar tobacco type, and is known to have a greater level of partial resistance to black shank than that exhibited by Florida $301(8,16,44)$. Unfortunately, it has been difficult to disassociate resistance in this line from cigar characteristics

Table 2. Disease severity index, percent root rot, and secondary inoculum production based on a Phytophthora nicotianae inoculation of tobacco breeding lines sorted into doubled-haploid (DH) groups and parental lines in greenhouse studies

\begin{tabular}{|c|c|c|c|c|c|c|c|}
\hline \multirow[b]{2}{*}{ Run } & \multirow[b]{2}{*}{ Group or parent $^{d}$} & \multicolumn{2}{|c|}{ Disease severity ${ }^{a}$} & \multicolumn{2}{|c|}{ Root rot $(\%)^{b}$} & \multicolumn{2}{|c|}{ Secondary inoculum (colonies/g) } \\
\hline & & Mean $\pm S E$ & $n$ & Mean $\pm S E$ & $n$ & Mean $\pm S E$ & $n$ \\
\hline 1 & $4 \mathrm{H} 8 \mathrm{H}$ & $8.3 \pm 0.1$ & 90 & $99 \pm 0$ & 90 & $61 \pm 5$ & 81 \\
\hline 1 & Hicks & $8.2 \pm 0.2$ & 10 & $100 \pm 0$ & 10 & $143 \pm 21$ & 9 \\
\hline 1 & $4 \mathrm{~B} 8 \mathrm{H}$ & $6.3 \pm 0.3$ & 110 & $94 \pm 2$ & 110 & $69 \pm 5$ & 99 \\
\hline 1 & $4 \mathrm{H} 8 \mathrm{~B}$ & $6.6 \pm 0.2$ & 118 & $96 \pm 1$ & 118 & $74 \pm 6$ & 108 \\
\hline 1 & 4B8B & $4.0 \pm 0.3$ & 109 & $75 \pm 3$ & 109 & $79 \pm 7$ & 99 \\
\hline 1 & $\mathrm{BH}$ & $1.4 \pm 0.3$ & 10 & $17 \pm 5$ & 10 & $132 \pm 16$ & 9 \\
\hline 2 & $4 \mathrm{H} 8 \mathrm{H}$ & $7.0 \pm 0.2$ & 90 & $100 \pm 0$ & 90 & $118 \pm 16$ & 81 \\
\hline 2 & Hicks & $7.6 \pm 0.3$ & 10 & $100 \pm 0$ & 10 & $175 \pm 34$ & 9 \\
\hline 2 & $4 \mathrm{~B} 8 \mathrm{H}$ & $5.4 \pm 0.3$ & 110 & $90 \pm 2$ & 110 & $202 \pm 16$ & 99 \\
\hline 2 & $4 \mathrm{H} 8 \mathrm{~B}$ & $4.5 \pm 0.3$ & 120 & $93 \pm 1$ & 120 & $229 \pm 18$ & 108 \\
\hline 2 & $4 \mathrm{~B} 8 \mathrm{~B}$ & $3.2 \pm 0.3$ & 110 & $69 \pm 3$ & 110 & $228 \pm 12$ & 99 \\
\hline 2 & $\mathrm{BH}$ & $2.0 \pm 0.7$ & 10 & $19 \pm 3$ & 10 & $325 \pm 47$ & 9 \\
\hline 3 & $4 \mathrm{H} 8 \mathrm{H}$ & $8.1 \pm 0.1$ & 90 & $100 \pm 0$ & 90 & $113 \pm 8$ & 81 \\
\hline 3 & Hicks & $8.4 \pm 0.3$ & 10 & $100 \pm 0$ & 10 & $125 \pm 27$ & 9 \\
\hline 3 & $4 \mathrm{~B} 8 \mathrm{H}$ & $6.4 \pm 0.3$ & 110 & $96 \pm 1$ & 110 & $130 \pm 8$ & 99 \\
\hline 3 & $4 \mathrm{H} 8 \mathrm{~B}$ & $6.1 \pm 0.3$ & 120 & $94 \pm 1$ & 120 & $125 \pm 9$ & 108 \\
\hline 3 & $4 \mathrm{~B} 8 \mathrm{~B}$ & $4.5 \pm 0.3$ & 110 & $81 \pm 2$ & 110 & $161 \pm 12$ & 99 \\
\hline 3 & $\mathrm{BH}$ & $0.0 \pm 0.0$ & 10 & $29 \pm 4$ & 10 & $159 \pm 26$ & 9 \\
\hline
\end{tabular}

${ }^{a}$ Disease severity was determined using incubation period after plants were inoculated with infested oat grains. Disease severity values assigned by incubation period in days. Severity values: $10=2$ to 5 days, $8=6$ to 9 days, $6=10$ to 13 days, $4=14$ to 17 days, $2=18$ to 21 days, and $0=$ greater than 21 days. $\mathrm{SE}=$ standard error of the mean and $n=$ the number of individuals evaluated in a group.

b Percent root rot was rated manually 21 days post inoculation.

c Secondary inoculum was determined by counting the number of CFU per gram of dry soil. Two soil samples were combined from each pot and three subsamples were used to determine propagules per gram of soil.

${ }^{\mathrm{d}} \mathrm{DH}$ group or parent; groups based on presence or absence of 'Beinhart 1000' (BH) resistance quantitative trait loci on linkage group 4 and 8.

Table 3. Linear contrasts of disease severity values between tobacco breeding lines sorted into doubled-haploid and parental groups after root inoculation with Phytophthora nicotianae in greenhouse studies ${ }^{\mathrm{a}}$

\begin{tabular}{|c|c|c|c|c|c|c|}
\hline \multirow[b]{2}{*}{ Group contrasts ${ }^{b}$} & \multicolumn{2}{|c|}{ Run 1} & \multicolumn{2}{|c|}{ Run 2} & \multicolumn{2}{|c|}{ Run 3} \\
\hline & MSE & $P>F$ & MSE & $P>F$ & MSE & $P>F$ \\
\hline 4H8H vs. $4 \mathrm{~B} 8 \mathrm{~B}$ & 911 & $<0.0001 *$ & 729 & $<0.0001 *$ & 670 & $<0.0001 *$ \\
\hline 4H8H vs. 4B8H & 192 & $<0.0001 *$ & 133 & $<0.0001 *$ & 155 & $<0.0001 *$ \\
\hline 4H8H vs. 4H8B & 157 & $<0.0001 *$ & 313 & $<0.0001 *$ & 220 & $<0.0001 *$ \\
\hline 4B8H vs. $4 \mathrm{H} 8 \mathrm{~B}$ & 3 & 0.4011 & 40 & $0.007 *$ & 5 & 0.342 \\
\hline $4 \mathrm{H} 8 \mathrm{H}$ vs. Hicks & 0 & 0.8671 & 3 & 0.436 & 1 & 0.725 \\
\hline 4B8H vs. 4B8B & 294 & $<0.0001 *$ & 266 & $<0.0001 *$ & 200 & $<0.0001 *$ \\
\hline $4 \mathrm{H} 8 \mathrm{~B}$ vs. $4 \mathrm{~B} 8 \mathrm{~B}$ & 369 & $<0.0001 *$ & 108 & $<0.0001 *$ & 149 & $<0.0001 *$ \\
\hline Hicks vs. BH & 231 & $<0.0001 *$ & 157 & $<0.0001 *$ & 353 & $<0.0001 *$ \\
\hline 4B8B vs. BH & 62 & $<0.0001 *$ & 12 & 0.128 & 182 & $<0.0001 *$ \\
\hline 4B8B vs. Hicks & 161 & $<0.0001 *$ & 180 & $<0.0001 *$ & 143 & $<0.0001 *$ \\
\hline 4H8H vs. BH & 430 & $<0.0001 *$ & 225 & $<0.0001 *$ & 595 & $<0.0001 *$ \\
\hline
\end{tabular}

a Data were analyzed using the PROC GLM command in SAS. Runs were analyzed separately. Disease severity was determined using incubation period after 5-week-old tobacco seedling roots were inoculated with infested oat grains. MSE $=$ mean square error and $P>F$ was the probability associated with the $F$ value. Numbers marked with an asterisk indicate the contrast between groups was statistically significant for $P<0.05$.

b Linear contrasts between groups with groups based on presence or absence of 'Beinhart 1000' (BH) resistance quantitative trait loci on linkage group 4 and 8. 
that are undesirable or unacceptable in other tobacco types (28). The focus of our investigation was on two $\mathrm{BH}$ genomic regions conferring black shank resistance, QTL on LGs 4 and 8, because they were found to be the major contributors to $\mathrm{BH}$ black shank resistance in the study by Vontimitta and Lewis (42). Interestingly, the BH QTL on LG 8 is also present in Florida 301 and possibly present in modern highly resistant flue-cured varieties (40-42). The QTL on LG 4 also exhibited a very large effect in the study of Vontimitta and Lewis (42). This QTL is not present in Florida 301 or current flue-cured or burley tobacco cultivars (40). Therefore, the QTL on LG 4 may represent a new source of genetic variability affecting partial resistance for tobacco growers if it can be separated from undesirable cigar tobacco traits $(28,42)$.

Incubation period is a standard measure used to compare the level of partial resistance present in a set of host cultivars when inoculated with a pathogen, or to compare the range of aggressiveness present in a set of pathogen isolates when inoculated on a host with partial resistance (34). A wide range of incubation periods was observed and expressed as severity values in the current study among the 45 host genotypes inoculated with a highly aggressive isolate of $P$. nicotianae. The greenhouse conditions used to conduct these tests were highly conducive for black shank development, with 35 and $25^{\circ} \mathrm{C}$ day and night temperatures, respectively, and frequent soil saturation periods favorable for sporangium formation and zoospore release $(15,24,30)$. The observed incubation period and severity index on susceptible Hicks was slightly higher in this study than in a previous study on pathogen aggressiveness; therefore, we concluded that our results are typical for a highly conducive greenhouse test (34).

Even under the favorable conditions of this study, however, the resistant parent had a low severity index in all experiments. These results agree with previous reports of high levels of partial resistance for BH in greenhouse and field studies $(8,16,28,36,44)$. DH lines with resistance QTL derived from BH on LGs 4 or 8 had significantly lower disease severity values compared with lines carrying corresponding genomic regions from Hicks on those LGs. Group 4B8B had the lowest severity index of all the $\mathrm{DH}$ groups but it was still significantly higher than the disease severity of $\mathrm{BH}$. This may be due to additional genomic regions in $\mathrm{BH}$ that contribute to resistance that were not present at a high frequency among the DH lines in this group (42). There were several lines in group $4 \mathrm{~B} 8 \mathrm{~B}$ that were similar to $\mathrm{BH}$ in disease severity but the mean of the group was significantly higher than the resistant parent.

One goal of this study was to determine if the QTL on LGs 4 and 8 acted in an additive manner to affect resistance. For disease severity, the difference between groups $4 \mathrm{~B} 8 \mathrm{H}$ and $4 \mathrm{H} 8 \mathrm{H}$ was 2.0 and between $4 \mathrm{H} 8 \mathrm{~B}$ and $4 \mathrm{H} 8 \mathrm{H}$ was 1.7 . The sum of these two values is very close to the difference between group $4 \mathrm{~B} 8 \mathrm{~B}$ and $4 \mathrm{H} 8 \mathrm{H}$, 4.3. Our greenhouse results correspond well with observations from a field study for end percent survival, in which these two QTL were observed to act in an additive fashion (42).

Table 4. Linear contrasts for percent root rot between tobacco breeding lines sorted into doubled-haploid and parental groups after root inoculation with Phytophthora nicotianae in greenhouse studies ${ }^{\mathrm{a}}$

\begin{tabular}{|c|c|c|c|c|c|c|}
\hline \multirow[b]{2}{*}{ Group contrasts $^{b}$} & \multicolumn{2}{|c|}{ Run 1} & \multicolumn{2}{|c|}{ Run 2} & \multicolumn{2}{|c|}{ Run 3} \\
\hline & MSE & $P>F$ & MSE & $P>F$ & MSE & $P>F$ \\
\hline 4H8H vs. 4B8B & 29,235 & $<0.0001 *$ & 48,082 & $<0.0001 *$ & 18,822 & $<0.0001 *$ \\
\hline $4 \mathrm{H} 8 \mathrm{H}$ vs. $4 \mathrm{~B} 8 \mathrm{H}$ & 1,365 & $0.011^{*}$ & 4,935 & $<0.0001 *$ & 982 & $0.026^{*}$ \\
\hline $4 \mathrm{H} 8 \mathrm{H}$ vs. $4 \mathrm{H} 8 \mathrm{~B}$ & 569 & 0.102 & 2,173 & $0.004 *$ & 1,982 & $0.002 *$ \\
\hline $4 \mathrm{~B} 8 \mathrm{H}$ vs. $4 \mathrm{H} 8 \mathrm{~B}$ & 212 & 0.318 & 697 & 0.101 & 177 & 0.344 \\
\hline 4H8H vs. Hicks & 1 & 0.945 & 1 & 0.950 & 0 & 1.00 \\
\hline 4B8H vs. 4B8B & 19,853 & $<0.0001 *$ & 24,677 & $<0.0001 *$ & 12,450 & $<0.0001 *$ \\
\hline 4H8B vs. 4B8B & 25,124 & $<0.0001 *$ & 34,919 & $<0.0001 *$ & 10,139 & $<0.0001^{*}$ \\
\hline Hicks vs. BH & 33,784 & $<0.0001 *$ & 33,211 & $<0.0001 *$ & 25,561 & $<0.0001 *$ \\
\hline 4B8B vs. BH & 30,291 & $<0.0001 *$ & 22,917 & $<0.0001 *$ & 24,787 & $<0.0001 *$ \\
\hline 4B8B vs. Hicks & 5,584 & $<0.0001 *$ & 9,096 & $<0.0001 *$ & 3,486 & $<0.0001 *$ \\
\hline 4H8H vs. BH & 60,319 & $<0.0001^{*}$ & 59,292 & $<0.0001 *$ & 46,010 & $<0.0001 *$ \\
\hline
\end{tabular}

a Data were analyzed using the PROC MIXED command in SAS. Percent root rot was rated 21 days post inoculation of 5-week-old tobacco seedlings with infested oat grains. MSE $=$ mean square error and $P>F$ was the probability associated with the $F$ value. Numbers marked with an asterisk indicate the contrast between groups was statistically significant for $P<0.05$.

b Linear contrasts between groups with groups based on presence or absence of 'Beinhart 1000' (BH) resistance quantitative trait loci on linkage group 4 and 8 .

Table 5. Linear contrasts for propagules per gram of dry soil between tobacco breeding lines sorted into doubled-haploid and parental groups after root inoculation with Phytophthora nicotianae in greenhouse studies ${ }^{\mathrm{a}}$

\begin{tabular}{|c|c|c|c|c|c|c|}
\hline \multirow[b]{2}{*}{ Group contrasts $^{b}$} & \multicolumn{2}{|c|}{ Run 1} & \multicolumn{2}{|c|}{ Run 2} & \multicolumn{2}{|c|}{ Run 3} \\
\hline & MSE & $P>F$ & MSE & $P>F$ & MSE & $P>F$ \\
\hline 4H8H vs. 4B8B & 14,020 & $0.025 *$ & 69,693 & 0.080 & 100,634 & $0.0003 *$ \\
\hline $4 \mathrm{H} 8 \mathrm{H}$ vs. $4 \mathrm{~B} 8 \mathrm{H}$ & 2,539 & 0.337 & 7,913 & 0.555 & 12,807 & 0.197 \\
\hline $4 \mathrm{H} 8 \mathrm{H}$ vs. $4 \mathrm{H} 8 \mathrm{~B}$ & 7,531 & 0.099 & 78,215 & 0.064 & 6,580 & 0.355 \\
\hline $4 \mathrm{~B} 8 \mathrm{H}$ vs. $4 \mathrm{H} 8 \mathrm{~B}$ & 1,401 & 0.476 & 39,861 & 0.185 & 1,308 & 0.680 \\
\hline 4H8H vs. Hicks & 53,596 & $<0.0001 *$ & 1,404 & 0.803 & 1,290 & 0.682 \\
\hline 4B8H vs. 4B8B & 5,141 & 0.172 & 34,042 & 0.221 & 46,267 & $0.014 *$ \\
\hline 4H8B vs. 4B8B & 1,283 & 0.495 & 125 & 0.941 & 65,480 & $0.004 *$ \\
\hline Hicks vs. BH & 480 & 0.676 & 100,422 & $0.036 *$ & 5,030 & 0.418 \\
\hline 4B8B vs. BH & 23,419 & $0.004 *$ & 77,095 & 0.066 & 18 & 0.961 \\
\hline 4B8B vs. Hicks & 33,375 & $0.0006^{*}$ & 22,927 & 0.315 & 10,053 & 0.253 \\
\hline 4H8H vs. BH & 40,853 & $0.0001 *$ & 150,305 & $0.010 *$ & 17,179 & 0.135 \\
\hline
\end{tabular}

a Data were analyzed using the PROC GLM command in SAS. Soil samples were taken 21 days post inoculation of 5-week-old tobacco seedlings with infested oat grains. Two samples were taken from each pot and combined. Propagules per gram of dry soil was determined by counting the number of colonies that formed after suspending infested soil over semiselective medium (PARPH). MSE $=$ mean square error and $P>F$ was the probability associated with the $F$ value. Numbers marked with an asterisk indicate the contrast between groups was statistically significant for $P<0.05$.

b Linear contrasts between groups with groups based on presence or absence of 'Beinhart 1000' (BH) black shank resistance quantitative trait loci on linkage group 4 and 8. 
The significant decrease in disease severity associated with BH QTL on LGs 4 and 8, in addition to evidence of their additivity, indicates that incorporation of the BH QTL on LG 4 in flue-cured and burley tobacco genotypes could significantly increase the level of partial resistance for growers. The mechanism of action of these two LGs is under further investigation.

There was a decrease in percent root rot in $\mathrm{BH}$ and $\mathrm{DH}$ lines from groups $4 \mathrm{~B} 8 \mathrm{H}, 4 \mathrm{H} 8 \mathrm{~B}$, and $4 \mathrm{~B} 8 \mathrm{~B}$. When $\mathrm{BH} \mathrm{QTL}$ on LGs 4 and 8 were combined into single genotypes, contributions to root rot resistance appeared greater than additive in this test. The polygenic resistance from $\mathrm{BH}$ greatly increased host resistance by preventing the rapid expansion of root lesions and delaying the development of symptoms. Highly susceptible DH lines and Hicks had a lower variance for root rot than the more resistant $\mathrm{DH}$ lines and $\mathrm{BH}$. Plants that were more susceptible died quickly and had $100 \%$ root necrosis. This would explain the low variance in group $4 \mathrm{H} 8 \mathrm{H}$ and Hicks. Plants with higher levels of resistance in the $4 \mathrm{~B} 8 \mathrm{H}$, $4 \mathrm{H} 8 \mathrm{~B}$, and 4B8B groups had more variance within their groups, as was observed for disease severity, which might be caused by differences in resistance expression among these genotypes.

High levels of root resistance in $\mathrm{BH}$ have been reported $(8,16,28,36,42,44)$. In our study, BH performed well even under high disease pressure. The pathogen was able to colonize the roots but the level of root rot remained relatively low. This low rot response may be due to inhibition of infection or suppression of lesion expansion. Because additional genes present in $\mathrm{BH}$ but not necessarily present in the genotypes studied may contribute to the high level of root resistance in this line, more work is needed to determine additional possible mechanisms of disease resistance present in $\mathrm{BH}(40,42)$.

In soils and environments that are favorable for growth and sporulation of $P$. nicotianae, development of the disease depends on the level of initial inoculum as well as the level of partial resistance of the host $(13,20,28)$. Black shank is a polycyclic disease and the rate of spread between plants has been related to level of host resistance (31). With high levels of resistance, high initial inoculum levels are required to cause high levels of disease (13). We observed high final inoculum levels on all genotypes in this study. In general, final inoculum levels were negatively correlated with the disease severity index. Because P. nicotianae reproduces primarily on live root tissue, genotypes that survived longest may have allowed the pathogen to produce higher total numbers of spores in the highly conducive conditions of this study. In fact, the highest inoculum densities were found in the root zones of $\mathrm{BH}$ and group 4B8B. Partially resistant varieties are frequently used in disease nurseries to increase inoculum levels instead of highly susceptible varieties, because they typically result in higher end-of-season populations of $P$. nicotianae (D. Shew, unpublished). In favorable environments, similar to the greenhouse conditions in our experiment, the pathogen would have produced multiple generations of spores, because $P$. nicotianae can produce zoospores every $72 \mathrm{~h}$ during favorable conditions (24). Inoculum densities for DH lines in groups $4 \mathrm{~B} 8 \mathrm{H}, 4 \mathrm{H} 8 \mathrm{~B}$, and $4 \mathrm{H} 8 \mathrm{H}$ were not significantly different from Hicks. Only $12 \mathrm{DH}$ lines had less than $90 \%$ root necrosis and, of those 12 lines, 10 belonged to group 4B8B. This suggests that the roots in DH groups other than $4 \mathrm{~B} 8 \mathrm{~B}$ had fewer roots and less tissue available for pathogen reproduction throughout the experiment. More experiments are needed to determine plant genotype effects on secondary inoculum under field conditions.

Significant levels of stem resistance to the black shank pathogen have only been associated with single-gene resistance from $N$. plumbaginifolia $(14,26,39,45)$. Stem resistance in BH and other varieties with high levels of partial resistance have been reported $(10,17,45)$ but Florida 301 and varieties derived from this source do not exhibit stem resistance $(17,45)$. We observed slightly smaller stem lesions on genotypes with the BH QTL on LG 4 (groups 4B8H and 4B8B). Interestingly, the only group not significantly different from Hicks and group $4 \mathrm{H} 8 \mathrm{H}$ was $4 \mathrm{H} 8 \mathrm{~B}$. These observations agree with previous reports that Florida 301 (which likely carries the resistance QTL on LG 8 but not LG 4) does not exhibit stem resistance to the pathogen $(10,17,45)$. Previously, when stem resistance in $\mathrm{BH}$ was compared with varieties with Florida 301 resistance, there were significant differences in lesion length $(17,45)$. This is the first report of a specific $N$. tabacum genomic region that is associated with stem resistance.

Based on previous research (45), variable inoculation methods can produce different results on the same variety. Plants that are deeply wounded in the pith and then inoculated will have more successful inoculation sites and larger lesions than those that are not wounded. In our experiment, plants were inoculated by pushing an infested toothpick through the stem (10). This created a large wound in the plant pith and the pathogen was able to quickly colonize stem tissues. Despite being inoculated in the pith, $\mathrm{BH}$ and $\mathrm{DH}$ lines in group 4B8B had smaller visible stem lesions than DH lines from other groups and Hicks. These results are additional evidence of contribution to stem resistance by the QTL on LG 4 from BH.

Black shank may occur on all parts of a tobacco plant $(24,32)$. Because the resistance from Florida 301 is expressed only in the roots, infections on stems and leaves may result in severe damage or death of the plant $(10,17,24)$. In contrast, the resistance to race 0 conferred by the Php gene is expressed in all host tissues $(10,16,17,36)$. In this study, lesions developed on leaves of all DH and parental lines following inoculation with zoospores of $P$. nicotianae. Infection efficiencies ranged from 25 to $100 \%$ on individual genotypes, with the resistant parent in the middle of the range, with $50 \%$ of the inoculation sites developing lesions. Resistance to $P$. nicotianae has been reported in leaves of $\mathrm{BH}$ and other tobacco lines, with some studies proposing that the resistance is associated with genes linked to the production of leaf-surface chemicals that could interfere with infection $(8,16,28,36,44)$. BH leaves had lower infection efficiencies than all DH groups except group 4B8B but were similar to those of the susceptible parent Hicks, which had an infection efficiency of 0.57 . In a previous experiment, leaves of $\mathrm{BH}$ did not develop lesions (36). In our study, however, neither LG appeared to contribute strongly to leaf resistance to $P$. nicotianae.

Tedford et al. (36) observed that susceptible tobacco varieties had increased disease severities with larger areas of necrosis compared with $\mathrm{BH}$ and other resistant varieties. In that study, apical leaves 7 to $9 \mathrm{~cm}$ in length were detached from 6-week-old seedlings and inoculated. In our study, leaves from nodes four to six on 8- to 9-week-old plants were inoculated. The differences observed between these studies might have been due to differences in leaf position and leaf age. We chose to inoculate older leaves further down the stem because these would most likely come in contact with infested soil during the part of the growing season when black shank typically develops.

Results from this study confirmed the high level of partial resistance to $P$. nicotianae conferred by the QTL on LGs 4 and 8 from $\mathrm{BH}$. A high level of root resistance was observed, resulting in decreased disease severity and root rot. Stem resistance to the pathogen was low and no resistance was observed in leaf tissue. In addition to the effects of QTL not investigated, root architecture, drought resistance, and other unknown mechanisms may also contribute to resistance observed in $\mathrm{BH}(19,20,42)$. We conclude that the QTL on LGs 4 and 8 contribute significantly to root resistance and the QTL on LG 4 would increase the level of resistance to $P$. nicotianae if incorporated into otherwise commercially acceptable varieties.

\section{Acknowledgments}

This research was supported by Philip Morris International, the Tobacco Education and Research Council, Inc., and the North Carolina Agricultural Research Service. We thank A. Mendoza-Moran for her technical assistance.

\section{Literature Cited}

1. Apple, J. L. 1957. Pathogenic, cultural, and physiological variation within Phytophthora parasitica var. nicotianae. Phytopathology 47:733-740.

2. Apple, J. L. 1962. Physiological specialization within Phytophthora parasitica var. nicotianae. Phytopathology 52:351-354.

3. Apple, J. L. 1967. Occurrence of race 1 of Phytophthora parasitica var. 
nicotianae in North Carolina and its implications in breeding for disease resistance. Tob. Sci. 11:79-83.

4. Breda de Hann, J. 1896. The root disease in deli-tobacco caused by Phytophthora nicotianae. Meded S Lands Plantentuin 15:1-107.

5. Burk, L., Gerstel, D., and Wernsman, E. 1979. Maternal haploids of Nicotiana tabacum from seed. Science 206:585-585.

6. Carlson, S. R., Wolff, M. F., Shew, H. D., and Wernsman, E. A. 1997. Inheritance of resistance to race 0 of Phytophthora parasitica var. nicotianae from the flue-cured tobacco variety Coker 371-Gold. Plant Dis. 81:12691274.

7. Chaplin, J. F. 1962. Transfer of black shank resistance from Nicotiana plumbaginifolia to flue-cured N. tabacum. Tob. Sci. 6:184-189.

8. Chaplin, J. 1966. Comparison of tobacco black shank (Phytophthora parasitica var. nicotianae) resistance from four sources. Tob. Sci. 10:55-58.

9. Csinos, A. S. 1994. Distribution of Phytophthora parasitica var. nicotianae races and their sensitivity to metalaxyl in Georgia. Plant Dis. 78:471-474.

10. Csinos, A. S. 1999. Stem and root resistance to tobacco black shank. Plant Dis. 83:777-780.

11. Csinos, A. S. 2005. Relationship of isolate origin to pathogenicity of race 0 and 1 of Phytophthora parasitica var. nicotianae on tobacco varieties. Plant Dis. 89:332-337.

12. Dukes, P. D., and Apple, J. L. 1961. Influence of host passage on virulence of Phytophthora parasitica var. nicotianae. Plant Dis. Rep. 45:362-365.

13. Ferrin, D., and Mitchell, D. J. 1986. Influence of initial density and distribution of inoculum on the epidemiology of tobacco black shank. Phytopathology 76:1153-1158.

14. Gallup, C. A., and Shew, H. D. 2010. Occurrence of race 3 of Phytophthora nicotianae in North Carolina, the causal agent of black shank of tobacco. Plant Dis. 94:557-562.

15. Gallup, C. A., Sullivan, M. J., and Shew, H. D. 2006. Black shank of tobacco. The Plant Health Instructor. Online publication. doi:10.1094/PHI-I2006-0717-01

16. Heggestad, H., and Lautz, W. 1957. Some results of studies on resistance to tobacco black shank. Phytopathology 47:452-452.

17. Hendrix, J. W., and Apple, J. L. 1967. Stem resistance to Phytophthora parasitica var. nicotianae in tobacco derived from $N$. longiflora and $N$. plumbaginifolia. Tob. Sci. 11:148-150.

18. Johnson, E. S., Wolff, M. F., Wernsman, E. A., Atchley, W. R., and Shew, H. D. 2002. Origin of the black shank resistance gene, $P h$, in tobacco variety Coker 371-Gold. Plant Dis. 86:1080-1084.

19. Jones, K. J. 1990. Components of resistance in Nicotiana tabacum to Phytophthora parasitica var. nicotianae. Ph.D. thesis, Department of Plant Pathology, North Carolina State University, Raleigh.

20. Jones, K. J., and Shew, H. D. 1995. Early-season root production and zoospore infection of cultivars of flue-cured tobacco that differ in level of partial resistance to Phytophthora parasitica var. nicotianae. Plant Soil 172:5561.

21. Kannwischer, M. E., and Mitchell, D. J. 1978. Influence of a fungicide on the epidemiology of black shank of tobacco. Phytopathology 68:1760-1765.

22. Kasperbaur, M., Collins, G. 1972. Reconstitution of diploids from leaf tissue of anther-derived haploids in tobacco. Crop Sci. 12:98-101.

23. Litton, C. C., Stokes, G. W., and Smiley, J. H. 1966. Occurrence of race 1 of Phytophthora parasitica var. nicotianae. Tob. Sci. 10:73-74.

24. Lucas, G. B. 1975. Diseases of Tobacco, 3rd ed. Biological Consulting Associates, Raleigh, NC

25. McIntyre, J. L., and Taylor, G. S. 1976. Screening tobacco seedlings for resistance to Phytophthora parasitica var. nicotianae. Phytopathology
66:70-73

26. McIntyre, J. L., and Taylor, G. S. 1978. Race 3 of Phytophthora parasitica var. nicotianae. Phytopathology 68:35-38.

27. Mila, A., and Radcliff, J. 2011. Managing diseases. Pages 143-163 in: Tobacco Information 2011. N. C. Coop. Ext. Serv. Bull. 187 (revised). North Carolina State University, Raleigh.

28. Nielsen, M. 1992. Sources of resistance to black shank and black root rot diseases. CORESTA Inf. Bull. 3/4:144-150.

29. Robin, C., and Guest, D. 1994. Characterization of pathogenicity of Phy tophthora parasitica isolates by stem and detached-leaf inoculations in 4 tobacco cultivars. Crop Hortic. Sci. 22:159-166.

30. Shew, H. D. 1983. Effects of soil matric potential on infection of tobacco by Phytophthora parasitica var. nicotianae. Phytopathology 73:1160-1163.

31. Shew, H. D. 1987. Effect of host resistance on spread of Phytophthora parasitica var. nicotianae and subsequent development of tobacco black shank under field conditions. Phytopathology 77:1090-1093.

32. Shew, H. D., and Lucas, G. B. 1991. Compendium of Tobacco Diseases American Phytopathological Society, St. Paul, MN.

33. Stokes, G. W., and Litton, C. C. 1966. Source of black shank resistance in tobacco and host reaction to races 0 and 1 of Phytophthora parasitica var. nicotianae. Phytopathology 56:678-680.

34. Sullivan, M. J., Melton, T. A., and Shew, H. D. 2005. Fitness of races 0 and 1 of Phytophthora parasitica var. nicotianae. Plant Dis. 89:1220-1228.

35. Sullivan, M. J., Melton, T. A., and Shew, H. D. 2005. Managing the race structure of Phytophthora parasitica var. nicotianae with variety rotation. Plant Dis. 89:1285-1294.

36. Tedford, E. C., Miller, T. L., and Nielsen, M. T. 1990. A detached-leaf technique for detecting resistance to Phytophthora parasitica var. nicotianae in tobacco. Plant Dis. 74:313-316.

37. Tisdale, W. B. 1931. Development of cigar wrapper tobacco resistance to black shank (Phytophthora nicotianae Breda de Haan). Univ. Fla. Agric. Exp. Stn. Tech. Bull. 226.

38. Valleau, W. D., Stokes, G. W., and Johnson, E. M. 1960. Nine years' experience with the Nicotiana longiflora factor for resistance to Phytophthora parasitica var. nicotianae in the control of black shank. Tob. Sci. 4:92-94.

39. van Jaarsveld, E., Wingfield, M. J., and Drenth, A. 2002. Evaluation of tobacco varieties for resistance to races of Phytophthora nicotianae in South Africa. J. Phytopathol. 150:456-462.

40. Vontimitta, V. 2010. Genetic mapping of genes controlling two leaf surface chemistry traits and identification of quantitative trait loci (QTL) associated with resistance to Phytophthora nicotianae in tobacco (Nicotiana tabacum L.). Ph.D. diss. North Carolina State University. http://www.lib.ncsu.edu/ resolver/1840.16/4686

41. Vontimitta, V., Danehower, D. A., Steede, T., Moon, H. S., and Lewis, R. S. 2010. Analysis of a Nicotiana tabacum L. genomic region controlling two leaf surface chemistry traits. Agric. Food Chem. 58:294-300.

42. Vontimitta, V., and Lewis, R. S. 2012. Mapping of quantitative trait loci affecting resistance to Phytophthora nicotianae in tobacco (Nicotiana tabacum L.) line Beinhart-1000. Mol. Breed. 29:89-98.

43. Wernsman, E. A., Matzinger, D. F., and Powell, N. T. 1974. Genetic investigations of intraspecific and interspecific sources of black shank resistance in tobacco. Tob. Sci. 18:15-18.

44. Wills, W. 1971. A comparison of black shank resistance of tobacco measured in inoculated whole plants and excised leaf tissue. Tob. Sci. 15:47-50.

45. Wills, W. H., and Moore, L. D. 1971. Response of some cultivars and lines of tobacco to stem inoculation with Phytophthora parasitica var. nicotianae. Tob. Sci. 15:51-53. 